\title{
LONG TEMPORAL VARIATION OF SEISMIC PARAMETERS FOP. SEISMIC PATTERNS IDENTIFICATION IN GREECE
}

\author{
Baskoutas I. ${ }^{1}$, Panopoulou G. ${ }^{1}$, Papadopoulos G. ${ }^{2}$ \\ ${ }^{1}$ National Observatory of Athens, P.O. Box 2004811810 Athens i.basko@.gein.noa.gr, \\ ${ }^{2}$ Earthquake Planning and Protection Organization, Seismotect. Div., Xanthou32, 15451 Athens
}

\section{ABSTRACT}

A new approach of detailed spatio-temporal variation analysis of seismic data is proposed by means of FastBEE (Fast estimation of Big Expected Earthquake) aiming at the regional monitoring of seismic activity for premonitory seismic patterns identification.

For the investigation of temporal variation, a set of seismic parameters is used, like the logarithm of the number of earthquakes $\log N$, estimates of $b$-value obtained by the maximum likelihood estimation model, time clustering of seismic activity $\Delta R(t)$ and of energy released $E^{2 / 3}$, since they can be considered as precursory seismological indicators. Earthquake catalog data, used in this approach, were elaborated in order to construct the time series for each parameter within a time window, large enough, as to guarantee statistical meaningful result.

The Hellenic trench-arc region under investigation is chosen in the basis of its seismotectonic characteristics, in relation to the spatial extent of the seismogenic zone.

The tools were tested, for long temporal variation features in the Ionian Islands Sea and the North Aegean Sea regions and its successful applicability is presented. The rise of irregularity, along these temporal profiles, was formulated in specific quantitative premonitory seismic pattern. In most of the cases, FastBEE premonitory pattern found shows significant changes from the background values of each parameter. Parameter $\log N$ shows a valley form curve, which start to increase before the expected earthquake occurrence, as well as the energy parameter $\mathrm{E}^{2 / 3}$, while b-value temporal estimates are forming a mountain shape curve, before the occurrence of a big earthquake. Instead, parameter $\Delta R(t)$ present a rapid fluctuation, without any kind of premonitory character

\section{INTRODUCTION}

Extensive researches on the general characteristics of earthquake precursors, particularly their time variation and spatial distribution, are extremely important in studying the earthquake prediction. Some theoretical and observational results about the temporal and spatial characteristics of seismic parameters, acting as precursors, (Gusev, 1976; Sobolev et al., 1991), have been formulated as premonitory seismicity patterns.

Thus several types of seismic patterns have been proposed (Habermann, 1981; Wyss, and Baer, 1981; Keilis-Borok, 1982; Caputo, et. al., 1983 ; Kossobokov and Carlson, 1995; Press and Allen, 1995; Shaw et al., 1997; Shebalin et al., 2000; Giovambatista and Tyupkin, 2000) world wide. In addition, for Greek territory seismicity patterns have been also proposed by (Papazachos, 1981; Papadimitriou and Papazachos, 1985; Karakostas et al., 1986). However, no premonitory seismic regularity has been firmly established yet.

Identification of additional seismic patterns, which may reflect the geodynamic characteristic in Greek territory, is the aim of this study. Thus long temporal variation of set of common seismic parameters, depicting the characteristic of the seismic activity was considered.

Such parameters comprise the number and the time clustering of earthquake occurrence, bvalue estimates and the energy released. Their character, as seismological indicators, is related to the seismogenic process and contains information that can be useful for seismic interpretation, as well as, in earthquake prediction. (Mogi, 1962; Aki, K., 1965; Utsu, 1965; Scholz, 1968; 
Papazachos, 1974; Papazachos, 1981; Kuznetsova et al., 1981; Smith, 1981; Molchan and and Dimitrieva, 1990; Wiemer and Wyss, 2002).

Long temporal variation of these common seismic parameters was monitored, to identify the presence of a seismicity pattern. Analysis were performed by the mean of new software, FastBEE (Fast expected Big Earthquake Estimation) tools, developed by Papadopoulos et al (2003) in several seismic active areas of Hellenic territory. The Hellenic trench-arc system (Papazachos and Comninakis, 1971; Comninakis and Papazachos, 1980), is seismically the most active tectonic system in the whole Mediterranean region. Defined areas, within this system, have been chosen to perform such temporal analysis, because of its geophysical, geodynamic and morphological character.

\section{SHORT DESCRIPTION OF FASTBEE SEISMIC PARAMETERS.}

Application of FastBEE tools was based on the temporal analysis of a set of four seismicity parameters, as they are described in the Papadopoulos et al., (2003). These parameters are the quantity $\log N$, i.e the number of earthquakes per unit time. Estimates of $b$-value, obtained by means of the maximum likelihood estimation method (Gusev, 1976; Van Wormer et al., 1976; Shoumilina, 1978), and the relationship proposed by Zavyalov and Sobolev, 1980, as follow:

$$
b=\lg \left[1+\frac{N_{\Sigma}}{\sum_{n=0}^{\infty} n N_{M_{\min +n M M}}}\right] / \Delta M
$$

With $\sigma_{b}=1 / \sqrt{N_{\Sigma}}$

where $N_{\Sigma}$ is the number of earthquakes in the time window considered for analysis; $N$ is the number of earthquakes in the magnitude range $M_{\min +n \Delta M} ; n=0,1,2,3,4 \ldots$ is the weighting factor , $\Delta_{M}$ is the unit of the magnitude range equal to 0.25 and $\sigma_{b}$ is the standard deviation of $b$ determination.

Spatial clustering of earthquakes $\Delta R(t)$, were obtained with following relationship:

$$
\Delta R(t)=\frac{1}{N_{t}} \sum_{i=1}^{N_{t}} \Delta r_{i}
$$

where

$$
\Delta r_{i}=\sqrt{\left(x_{i-1}-x_{i}\right)^{2}+\left(y_{i-1}-y_{i}\right)^{2}+\left(z_{i-1}-z_{i}\right)^{2}}
$$

and energy released as:

$$
\bar{E}(t)=\sum_{i=1}^{N_{t}} E_{i}^{2 / 3}
$$

where energy $E$ is derived using the relationship, $\log E=1.5 M_{s}+4.7$, proposed by Papazachos and Papazachos (2000) for Greek territory. 


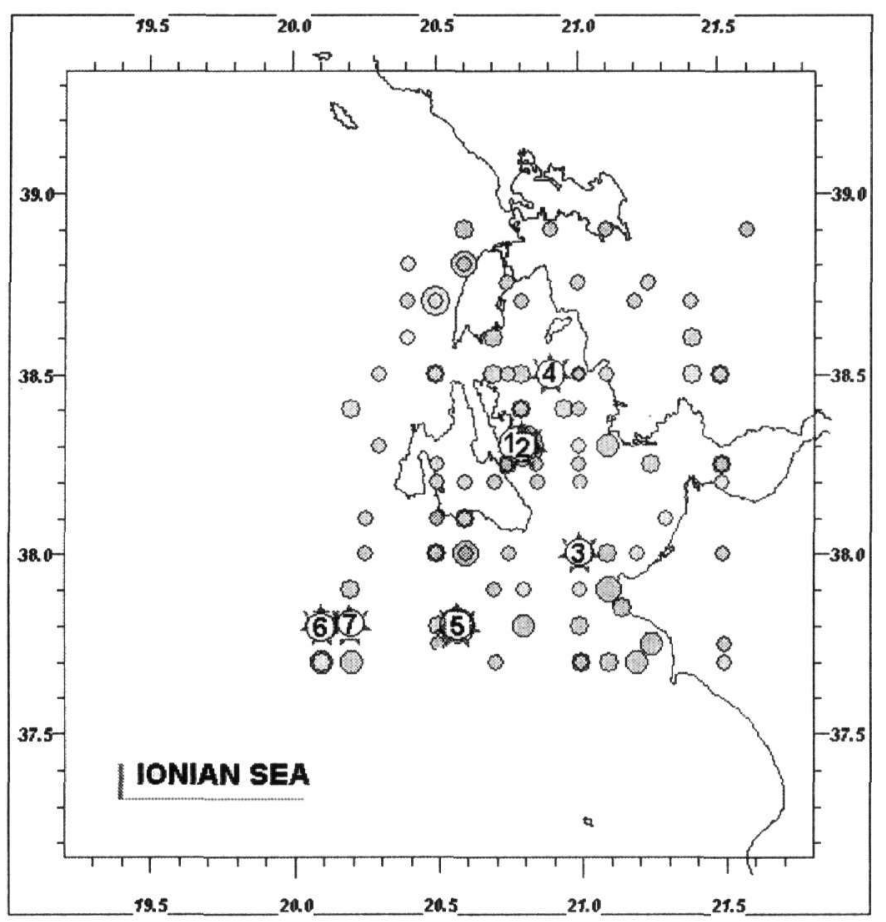

Figure 1a. Seismicity map in the lonian Sea region during 1943-1963. Stars with number show the main events reported in the table 1 )

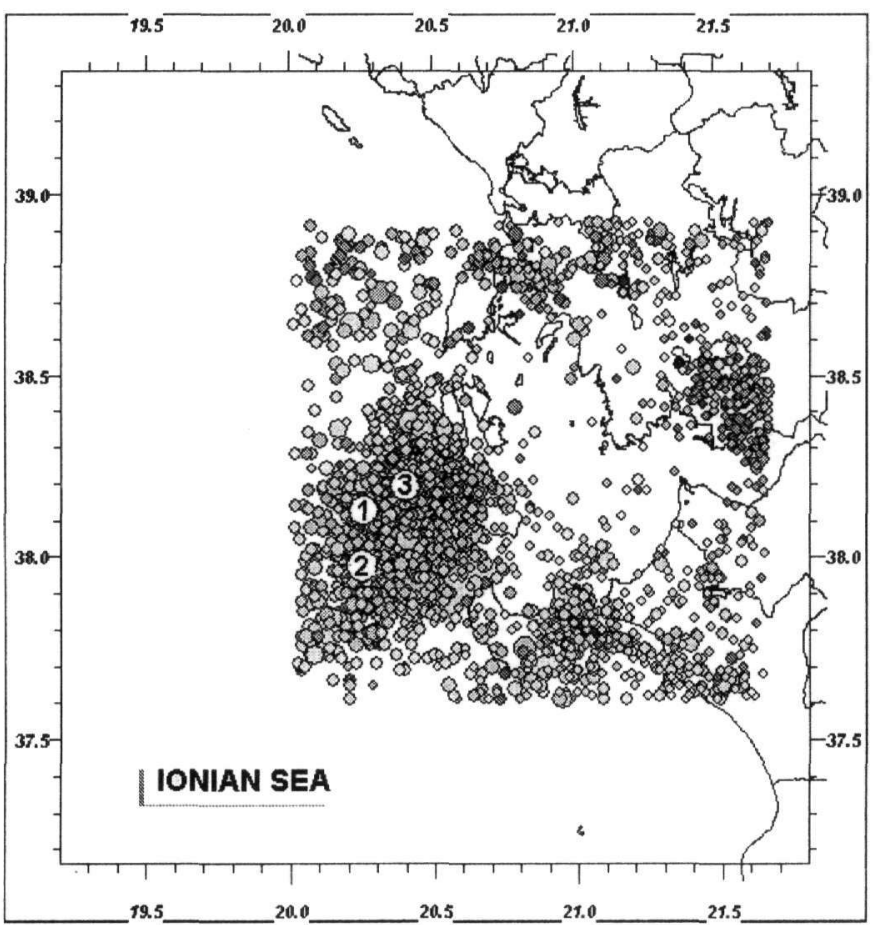

Figure 1b. Seismicity maps in the Ionian Sea region during 1966-1989. Stars with number show the main events reported in the table 2) 


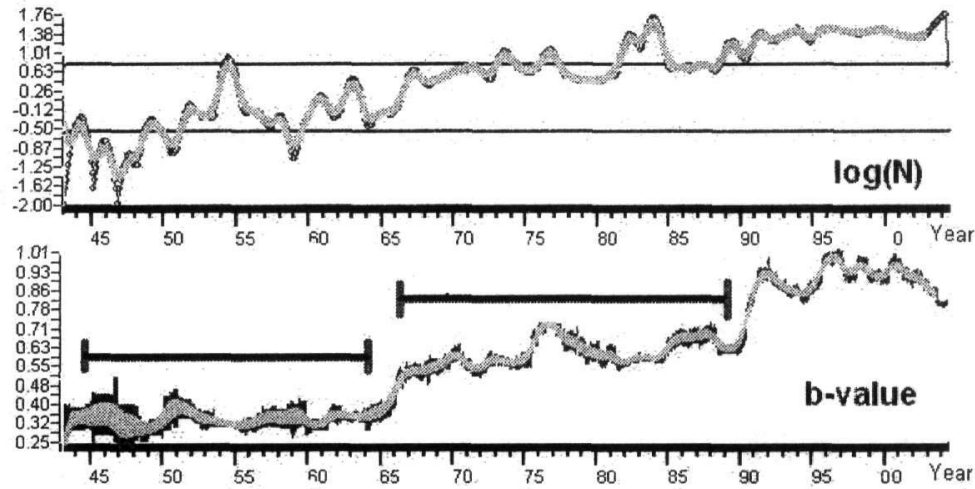

Figure 2. Long temporal variation of $\log N, b$-value estimates for the period 1943-2004, in the Ionian Sea region. Segments on b-value graph, shows the period of analysis (1943-1963 and 1966-1990)

\section{CASE STUDY IN THE IONIAN SEA AND NORTH AEGEAN SEA REGIONS.}

FastBEE tools, was applied for long and short time interval, covering the period of the instrumental seismological observation in Greece, i.e. from 1900 to present, in two regions of Greece, which have been affected by a series of strong earthquakes in the $20^{\text {th }}$ century, August 12 , 1953 Kephalonia and August 6, 1983 Lemnos earthquakes. The long temporal variation analysis at Ionian Sea region and North Aegean Sea comprises three periods, 1943 to1962, 1966 to1989 and 1970 to 1990 respectively.

An area of about $70 \mathrm{Km}^{2}$ under investigation, in both regions are defined by the coordinates $37.6 \mathrm{~N}, 38.9 \mathrm{~N}, 20.0 \mathrm{E}, 21.5 \mathrm{E}$ and $39.3 \mathrm{~N}, 40.6 \mathrm{~N}, 24.0 \mathrm{E}, 25.6 \mathrm{E}$, in order to cover the seismogenic area of the examined earthquakes. In figures $1 \mathrm{a}, 1 \mathrm{~b}$ and $1 \mathrm{c}$ the seismicity maps for all three periods, 1943-1963 and 1966-1989 for Ionian Sea, and 1970-1990 for North Aegean Sea regions respectively, can be seen. Afterwards no significant seismic activity with strong earthquakes exists in the examined areas. Before 1943 and 1970 for the Ionian Sea and the north Aegean Sea regions respectively, analysis can not be performed because of the lack of data (figure 2).

Results of these analyses are shown in the figures 3,4 and 5 respectively. Output graph of the seismic parameters drawings with their respective standard errors can be shown, in figure 3,4 and 5 . In the same graph the mean value (dashed line, parallel to time axis) of the respective parameter for the entire examined time period and standard error $1 \sigma$ (continue lines parallel the mean line, in both sides) can be also shown, as well as the number and magnitude of main strong earthquakes. Seismic parameters of these earthquakes for both areas and periods are reported in tables 1,2 and 3. Large standard errors of $b$-value in figures 3 and 5 , reflect the data deficiency, but still they are in the limits of the acceptance, showing thus the clear regular fluctuation of the temporal variation especially for b-value and energy released.

Long temporal variation of the parameters estimates depicts a repeating regular wavy form characteristic pattern. Qualitatively this pattern can be described by the clear and regular fluctuation, which rise and fall in each time series signalize the earthquake occurrence. Namely, $b$ value estimates, shows a clear mountain shape form and fore coming earthquake to be localized at the end right slope.

In the opposite parameter $E^{2 / 3}$ passes a minimum, of a valley shape form, before the strong earthquake occurrence and then increase as seismic activity develops further to the aftershock activity. $\Delta R(t)$ clustering doesn't show a regular course, limited extension of the area under investigation, geodynamic complexity and differences of the distinct nature of the region's seismicity may be reflects its temporal behavior. Quantity $\log N(t)$ pattern, in most of the cases, shows the same behavior as parameter $E^{2 / 3}$ forming a valley, before the strong earthquake occurrence, indicating somehow a seismic quiescence. Parameter $\Delta R(t)$ seems to be more sensitive on the seismotectonic geometry and on the period of formation of the earthquake source, which can involve complex and rapid fluctuation of the parameters considered (Ponomarev et al., 1997). 


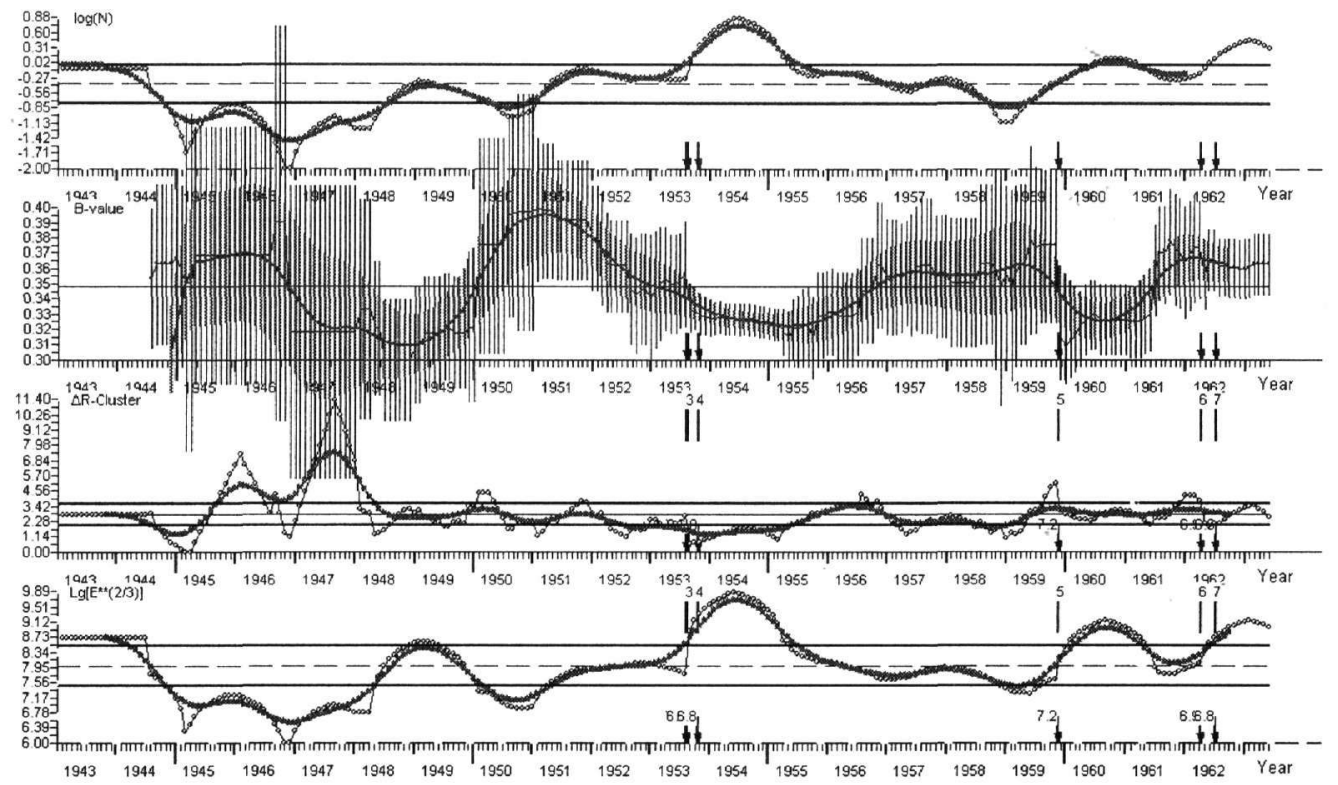

Figure 3. Long temporal variation of $\log N, b$-value estimates, $\Delta R(t)$ and $E^{2 / 3}$ seismic parameters for the period 1943-1963, in the Ionian Sea region.

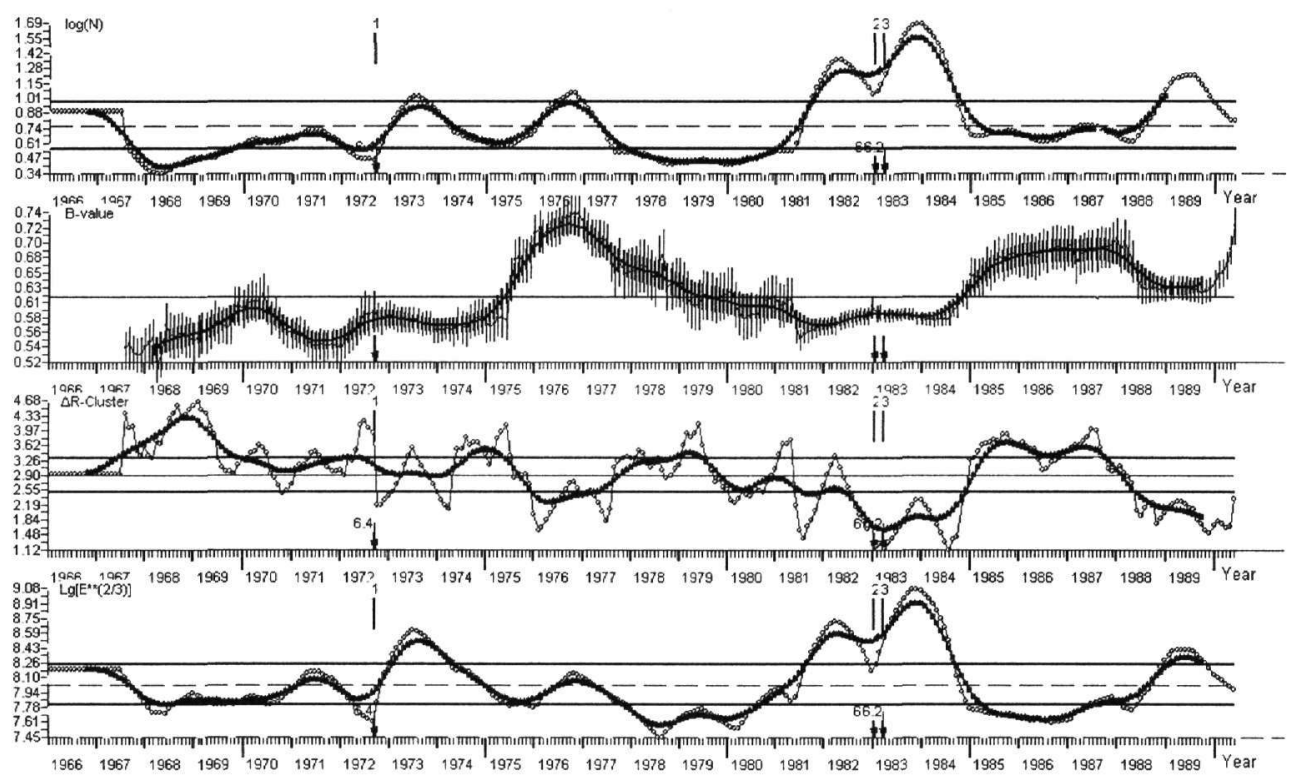

Figure 4. Long temporal variation of $\log N, b$-value estimates, $\Delta R(t)$ and $E^{2 / 3}$ seismic parameters for the period $1966-1990$ in the Ionian Sea region. 


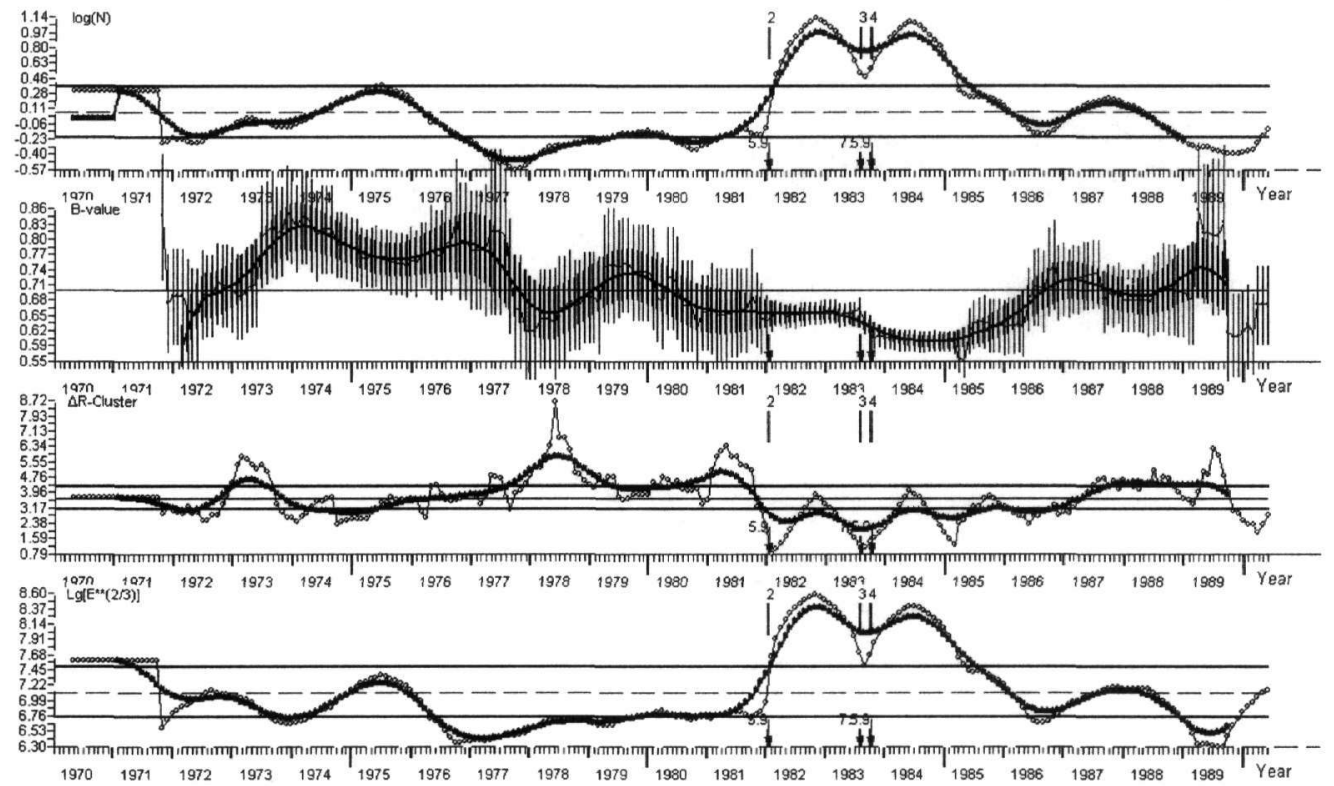

Figure 4. Long temporal variation of $\log N(t), b$-value estimates, $\Delta R(t)$ and $E^{2 / 3}$ seismic parameters for the period 1970-1989, in the North Aegean Sea region.

Table 1. Strong earthquakes parameters, for the Ionian sea area of figure 1a, during 1943-1963.

\begin{tabular}{lrrrrrrr}
\hline Year & Month & Date & Origin time & Lat & Lon & Depth & Ms \\
\hline 1953 & Aug & 11 & 033222.0 & 38.30 & 20.80 & 10 & 6.7 \\
1953 & Aug & 12 & 092352.0 & 38.30 & 20.80 & 10 & 7.2 \\
1953 & Aug & 12 & 120521.0 & 38.00 & 21.00 & 10 & 6.3 \\
1953 & Oct & 21 & 183952.0 & 38.50 & 20.90 & 5 & 6.3 \\
1959 & Nov & 15 & 170843.0 & 37.80 & 20.57 & 10 & 6.7 \\
1962 & Apr & 10 & 21377.0 & 37.80 & 20.10 & 10 & 6.4 \\
1962 & Jul & 6 & 091616.0 & 37.80 & 20.20 & 10 & 6.3 \\
\hline
\end{tabular}

Table 2. Strong earthquakes parameters, for the lonian sea area of figure 1b, during 1962-1989.

\begin{tabular}{rrrrrrrr}
\hline Year & Month & Date & Origin time & Lat & Lon & Depth & Ms \\
\hline 1972 & Sep & 17 & 140713.1 & 38.12 & 20.25 & 5 & 5.9 \\
1983 & Jan & 17 & 124130.9 & 37.97 & 20.25 & 9 & 6.2 \\
1983 & Mar & 23 & 235107.6 & 38.19 & 20.40 & 10 & 5.7 \\
\hline
\end{tabular}

Table 3. Strong earthquakes parameters, for the North Aegean Sea area of figure 1c, during 1970-1990.

\begin{tabular}{cllllllll}
\hline Year & \multicolumn{2}{c}{ Month } & \multicolumn{2}{c}{ Date } & \multicolumn{2}{c}{ Origin time } & \multicolumn{3}{c}{ Lat } & \multicolumn{3}{c}{ Lon } & Depth & Ms \\
\hline 1982 & JAN & 18 & 192724.9 & 39.78 & 24.48 & 5 & 6.3 \\
1982 & JAN & 18 & 193114.9 & 40.01 & 24.31 & 29 & 5.4 \\
1983 & AUG & 6 & 154353.3 & 40.08 & 24.81 & 22 & 6.6 \\
1983 & OCT & 10 & 101657.9 & 40.44 & 25.43 & 8 & 5.4 \\
\hline
\end{tabular}




\section{CONCLUSIONS}

Long temporal variation analysis with FastBEE tools in the Hellenic territory have shown the existence of clear premonitory seismicity pattern, which in most of the cases, shows remarkable change in the basic characteristics of the seismicity. Fluctuation of the parameters considered depict the rise of irregularity in time, which was formulated in a specific qualitative premonitory seismic pattern (FastBEE premonitory seismic pattern) for the examined seismogenic areas.

It is remarkable to mention that this pattern is not sensitive to the extension and area shape, arbitrary in some sense, definition, but to the geodynamic regime, which dominate over the entire region. In this sense regions with distinct nature of the seismicity (or distinct geodynamic features) and period of formation of the earthquake source, affect time clustering patterns, producing complex and rapid fluctuation of its behavior.

Moreover are still not formulated the quantitative features of FastBEE pattern. Application should extent in different seismogenic zones in Greece and abroad in order to formulate accurately its temporal premonitory behavior. Geophysical and seismotectonic information may can contribute to effort

\section{ACKNOWLEDGEMENTS}

This work has been carried out within the frame of the bilateral scientific and technological collaboration between Greece and Russia 2002-2004, supported by the General Secretary of Research and Technology, Greece (code number 2617/13-03-2002).

\section{REFERENCES}

Aki K. 1965. Maximum likelihood estimate of $b$-value in the formula $\log N=a-b M$ and its confidence limits, Bull. Earthq. Res. Inst. 43, 237-239pp.

Caputo M. Console R. Gabrielov A. M. Keilis-Borok V. I. and Sidorenko T. V.,1983. Long-term premonitory seismicity patterns in Italy. Geophys. J. R. Astron. Soc., 75: 71-75.

Comninakis P. E. and Papazachos B. C. 1980. Space and time distribution of the intermediate focal depth earthquakes in the Hellenic arc. Tectonophysics, 70, 35-47.

Comninakis P. E. and Papazachos B. C. 1986. A catalog of earthquakes in Greece and the surrounding area for the period 1901-1985. Thessaloniki, pp. 167.

Giovambatista Tyupkin R. and Yu .S. 2000. Seismicity patterns before several damaging earthquakes in central Italy in September-October, 1997. Vole. Seis. . Vol. 21. 511-517.

Gusev A. A. 1976. Indicator earthquakes and prediction. In Seismicity and Deep Structure of Siberia and Far East, Nauka, Novosibirsk, 1976 (in Russian), 241247.

Habermann R. E. 1981. Precursory seismicity patterns: Stalking the mature seismic gap. In Earthquake Prediction: An International Review (eds. Simpson, D. W., and Richards, P. G.) (American Geophysical Union, Washington, D.C. 1981) 29-42.

Keilis-Borok V. I. 1982. A worldwide test of three long-term premonitory seismicity patterns: A review. Tectonophysics, 85: 47-60.

Karakostas B. G. Hatzidimitriou P. M. Karakaisis G. F. Papadimitriou E. E. and Papazachos B. C. 1986. Evidence for long term precursors of strong earthquakes in the northernmost part of the Aegean Sea. (Earth.Pred.Research, 4, 155-164pp.

Kossobokov V. G. and Carlson, J. M. 1995. Active zone size vs. activity: A study of different seismicity patterns in the context of the prediction algorithm M8. J. Geophys. Res., 100, 0431-0441.

Kossobokov V. G. and Shebalin P. N. 2003. In "Keilis-Borock V. I and A. A. Soloviev., 2003. Nonlinear Dynamics of the lithosphere and earthquake prediction" Springer Publications.

Kuznetsova, K., I., Shumilina L., S., and Zavyalov A., D. 1981. The physical sense of the magnitude-frequency relation. // Proceed, of the $2^{\text {nd }}$ Inter. Sympos. on the analysis of seismicity and on seismic hazard. Liblice, Czechoslovakia, May 18-23, 1981, 27-46pp.

Mogi K. 1962. Study of elastic shocks caused by the fracture of geterogeneos materials and its relation to earthquakes phenomena. Bull. Earthq. Res. Inst. 40,1, 125-173.

Molchan G.,and Dimitrieva. M. 1990. Dynamics of the magnitude-frequency relation for foreshocks. Phys. Earth Planet. Int., 6,1 99-112. 
Papadimitriou E. E. and Papazachos, B. C. 1985. Evidence for precursory seismicity patiarns in the lonian islands (Greece). Earth. Pred. Res., 3, 95-103.

Papadopoulos Georg. An. Baskoutas I. G. and Stavrakakis G. N., 2003. Tools for the fast Estimation of Expected Big Earthquake in predefined seismic prone areas. Abstract, Proceedings of the First International Workshop for Earthquake Prediction. Athens 2003.

Papadopoulos An. Georg. and Baskoutas G. I. 2004. Seismic parameters tools analysis for the Fast Big Expected Earthquake estimation (FastBEE). Natural Hazard, (Under revision).

Papazachos B. C. and Comninakis P. E. 1971. Geophysical and Tectonic features of the Aegean arc. J. Geophys. Res., 76, 8517-8533.

Papazachos C. B. and Papazachos B. C. 2000. Accelerated preshock deformation of brnad regions in the Aegean area. Pure and Appl. Geophys. 157, 163-1681.

Papazachos B. C. 1981. The time variation of the difference in magnitude between the main shock and its largest aftershock as long-term premonitory pattern of strong earthquakes. Quat. Geod., 2, 111-117.

Papazachos B. C. 1974. Dependence of the seismic parameter b on the magnitude range. Pure appl. Geophys. $112,1059-1065$.

Papazachos B. C. 1981. The time variation of the difference in magnitude between the main shock and its largest aftershock as long-term premonitory pattern of strong earthquakes. Quat. Geod., 2, 111-117.

Ponomarev A. V. Zavyalov A. D. Smirnov V. B. and Lockner D. A. 1997. Physical modelling of the formation and evolution of seismically active fault zones. Tectonophysic, $277,57-81$.

Press F. and Allen C. 1995. Patterns of seismic release in the southern California region. .7. Geophys. Res., 100(B4), 421, 6430.

Scholz C. H. 1968. The frequency - magnitude relation of raicrofracturing in rock and its relation to earthquakes. "Bull. Seism. Soc. Am.", 58, $39-415$.

Shebalin P. N. Zaliapin I. and Keilis-Borok V. I. 2000. Premonitory raise of the earthquakes' correlation range: Lesser Antilles. Phys. Earth Planet. Int., 122, 241-249.

Shaw B. E. Carlson J., M. and Langer J. S. 1997. Patterns of seismic activity preceding large earthquakes. J. Geophys. Res., 97, 479.

Shoumilina L. S. 1978. Seismic Hazard in Kamchatka and Komandorsky island. PHD Thesis. Moscow, pp, 198.

Smith W. D. 1981. The b-value as an earthquake precursor. Nature, 289, 5794, 36-139.

Sobolev G. A. Chelidze. T. L. and Zavyalov A. D. 1991. Map of expected earthquakes based on a combination of parameters, Tectonophysics, 193, 255-266.

Utsu T. 1965. A method for determining the $b$ value in a formula logn=a-bM showing the magnitude -frequency relation for earthquakes. Geoph. Bull. Hokkaido Univ. 13, 99-103.

Van Wormer J. D. Gedney L. D. Davies J. N. Condal N. 1976. Vp/Ns and b-values: a test of the dilatancy model for earthquakes precursors. Geophys. Res. Lett. 2, 11, pp.514-516.

Wiemer S. and Wyss M. 2002. Spatial and temporal variability of the b-value in seismogenic volumes: An overview, Advances in Geophysics, 45, 259-302.

Zavialov A. D. and Sobolev G. A. 1980. Some regularities of seismic regime and earthquake prediction. Proc. $17^{\text {th }}$ Gen. Assembly of ESC. Budapest. 65-69.

Wyss M. and Baer M. 1981. Seismic quiescence in the western Hellenic arc may foreshadow large earthquakes. Nature, 289: 785-787. 